\title{
Um modo de significar a formação docente pelo olhar do professor-formador
}

A way of signifying the teacher training by the teacher-trainer's view

\author{
Adriana Ofretorio de Oliveira Martin MARTINEZ *
}

\begin{abstract}
RESUMO: As qualidades descritivas e reflexivas da escrita narrativa permitem, ao sujeito que a escreve, adentrar nas dimensões históricas e sociais de sua trajetória profissional e nas interrelações que o formam. Esse tipo de escrita torna-se um modo possível de se questionar os sentidos das práticas profissionais e transgredir possíveis ações que não se modificam. Partindo desse contexto, o presente trabalho propõe tecer um diálogo sobre os sentidos e significados que perpassam as dinâmicas de formação continuada de professores, mas pelo olhar de quem as planejou - sujeito que denominamos como professor-formador. Para tanto, com o aporte teórico da psicologia HistóricoCultural e metodológico do paradigma indiciário, analisaremos as narrativas reflexivas escritas de uma professoraformadora, elaboradas a partir de suas experiências como responsável por cursos de formação continuada sobre a prática pedagógica para professores e educadores de uma rede pública de ensino paulista. A narrativa escrita das experiências da professora-formadora se tornou um modo de elaborar novos planos de ação formativas diante daquilo que ela observou ser importante para os professores e educadores aprenderem sobre o planejamento pedagógico nos cursos. Assim, o conceito de formação, como algo dinâmico e a ser construído no percurso, tornou-se motivo de reflexão.
\end{abstract}

PALAVRAS-CHAVE: Significação. Narrativa reflexiva. Formação continuada. Formação de professores.
ABSTRACT: The descriptive and reflective qualities of narrative writing allow, to the subject who write it, go into in the historical and social domensions of their professional trajectory and in interrelations that form it. Therefore, it becomes a possible way of questioning the of his professional practice and transgressing possible actions that do not change. Based on this context, the present work proposes to make a dialogue about the meanings and senses that permeate the dynamics of continuing education of teacher, but by the view of those who planned them - the subject we call as teacher- trainer. For this purpose, with the theorical contribuition of the historical Cultural Psychology and indicting paradigm methodological, we will analyze the written reflexive narratives of the teacher-trainer from her experiences as responsible for continuing training courses on pedagogical practice for teacher snd educator of a public education network in São Paulo. The written narrative of the teacher- trainer's experience became a way of elaborating new plans of formative actions in view of what she observed that it was important for teachers and educators to learn about pedagogical planning in the courses. Thereby, the concept of formation, as something dynamic and to be built in the course became the reason for reflection.

KEYWORDS: Signification. Reflective narrative. Continuing education. Teacher training.

\footnotetext{
* Doutoranda em Psicologia Educacional pela Faculdade de Educação da Universidade Estadual de Campinas. Membro do Grupo de Pesquisa Pensamento e Linguagem (GPPL), ORCID: https://orcid.org/0000-0002-6870$\underline{371 X}$. E-mail:: aofretorio@gmail.com.
} 


\section{Introdução}

O presente artigo se insere na temática da formação continuada do professor, porém, buscamos ampliar o diálogo para além do desenvolvimento profissional dos sujeitos professores quando participam de cursos formativos. Para tanto, propomos uma reflexão sobre o processo de significação, ou seja, de produção de sentidos sobre a formação continuada do professor pelo olhar do sujeito que elabora esse contexto de desenvolvimento profissional, o qual denominamos como professor-formador ${ }^{1}$. Dado esse objetivo, valemo-nos de alguns textos narrativos reflexivos produzidos por uma professora-formadora sobre as suas próprias experiências em três momentos distintos de planejamento e reflexão a partir de um trabalho realizado em cursos sobre o planejamento de atividades pedagógicas para a Educação Infantil, oferecidos nos anos de 2012 e 2013 para professores e educadores de uma rede pública municipal paulista.

A partir desses escritos, questionamos: quais processos de significação podemos identificar nas narrativas de uma professora-formadora sobre a organização pedagógica de um curso para professores e educadores? De que modo essa significação contribuiu para a organização da ação formativa da professora-formadora e como isso reverbera em seu olhar sobre o referido processo?

Para desenvolver essas questões, ancoramo-nos no conceito de desenvolvimento humano considerando sua constituição materialista, histórica e dialética fundamentadas nas relações sociais mediadas pela linguagem. Nessa perspectiva, considerando que

o homem se constitui não por uma absorção imediata do meio, mas por um processo constante de subjetivação da realidade que o torna único; neste processo de subjetivação, o mundo objetivo é convertido para o subjetivo, produzindo-se um plano interno pela incorporação do externo, processo em que se configura algo novo (ROSA; ANDRIANI, 2011, p. 272).

Por isso, reforçamos, em nossa discussão, ser imprescindível refletir sobre o processo de significação da professora-formadora levando em conta todas as experiências e os significados sociais sobre a formação docente que ela revela em seus escritos.

\footnotetext{
${ }^{1}$ Inserimos no texto o hífen na grafia de "professor-formador" unicamente por compreender que, na experiência base deste texto, a formadora era também professora de Educação Infantil no contraturno do curso. Então, os sentidos contidos em cada palavra isolada, de professor e de formador, unem-se para exemplificar o significado complexo e único do universo de sua prática.
} 
Em vista disso, utilizamos, para o processo de análise: a metodologia de organização dos dados pelo paradigma indiciário de Ginzburg (2003), o qual revela que todo objeto de investigação pode ser compreendido pelos seus indícios; e a teoria de desenvolvimento humano e constituição psicológica representada pelos estudos de Vygotsky (2008), especificamente o conceito de significação, ou seja, no processso semiótico, mediado pela linguagem, no qual os sentidos, que mobilizam o pensamento e a consciência, são elaborados pelos sujeitos por meio das relações sociais.

Considerando a importância da reflexão na coletividade docente como modo de esse sujeito "valorizar e dialogar com situações, analisando informações sobre elas, tomando decisões sob o que fazer e ainda, observando o efeito desse processo e ações no trabalho por ele desenvolvido em um determinado tempo e contexto sócio-histórico e cultural" (SADALA, SÁ-CHAVES, 2008, p.190), ressaltamos que a escrita da professora-formadora sobre sua experiência entrelaça-se às suas vivências com o coletivo de professores dos cursos que ofereceu; portanto, indiretamente, a problematização de sua prática é constituída por tal coletivo, que afeta e constitui esse professor-formador.

Assim, o presente artigo revela-se, também, uma auto-análise do trabalho pedagógico, ou seja, insere-se na modalidade de pesquisa do professor-pesquisador, na qual o sujeito que investiga é o próprio professor. Com isso, este professor tona-se pesquisador ao produzir conhecimento sobre sua prática e as relações que a constituem, por meio de práticas de pesquisa, confluindo para um processo de problematizações, com vistas à transformações substanciais dessas ações (LÜDKE, 2001, ZEICHNER, 1998) Por isso, a análise do processo de significação da formação continuada docente pelo professor-formador será realizada por meio de narrativas nas quais os indícios desse processo serão evidenciados.

\section{A formação continuada do professor em serviço}

A formação continuada de professores tem sido um tema muito recorrente nas investigações do campo educacional, e isso é expressivo nos inúmeros trabalhos de pesquisa da pós- graduação, nos últimos anos, direcionados a essa temática² ${ }^{2}$.

\footnotetext{
${ }^{2}$ O Encontro Nacional de Didática e Prática de Ensino (ENDIPE), o Congresso Estadual Paulista sobre Formação de Educadores (CEPFE) e os eventos da ANPEd, regionais ou nacionais, são exemplos de eventos cujos trabalhos relacionados à formação de professores assumem uma expressividade diante dos demais temas relacionados à educação.
} 
Ao nosso ver, essa grande demanda reflete a importância de se compreender como é constituída a prática do profissional docente em serviço, e de que maneira um contexto de formação constitui e reverbera a profissionalidade desse professor, porque mudanças em seu comportamento profissional ou nos sentidos que permeiam suas escolhas pedagógicas (crenças, valores, sentidos sobre o ensinar, conceitos de desenvolvimento humano) afetam diretamente o cotidiano pedagógico de sua sala de aula e, consequentemente, seus alunos. Além disso, se o professor assume sua prática como uma práxis social, ou seja, como uma ação consciente para a mudança da realidade escolar nos mais diversos aspectos culturais e sociais, ele está assumindo um modo outro de mediação entre sujeito e conhecimento, que conduz seus alunos à elaboração de um pensamento crítico e proativo.

A partir da filosofia da práxis marxista (VÁZQUEZ, 1977), de cujos pressupostos teóricos nos aproximamos, defendemos que a formação continuada do professor é uma atividade humana, realizada em situações concretas, que mobiliza a consciência do sujeito. Desse modo, por se tratar de uma atividade, "só existe através do homem, como produto de sua consciência. Toda ação verdadeiramente humana requer certa consciência de uma finalidade, finalidade que se sujeita ao curso da própria atividade” (VÁZQUEZ, 1977, p. 189) e ainda:

se desenvolve como produção de objetivos que prefiguram idealmente o resultado real que se pretende obter, mas se manifesta, também, como produção de conhecimentos, isto é, em forma de conceitos, hipóteses, teorias ou leis mediante os quais o homem conhece a realidade. (VÁZQUEZ, 1977, p. 191)

Por isso, um processo de formação do professor em serviço, ou em formação continuada, mobiliza a produção de sentidos sobre a realidade concreta, bem como sobre as atividades vinculadas a essa profissão, tendo como finalidade ações transformadoras dessa realidade escolar.

Muitas pesquisas na área da formação continuada de professores (ANJOS, 2013; ANJOS E DAINEZ, 2018; ARAUJO, 2006; BUSCARIOLO; 2015; BRITO E ARAUJO, 2018; LOPRETTI, 2013), mesmo assumindo diferentes estratégias para a reflexão e problematização da experiência profissional e didática do professor, apoiam-se na premissa apontada anteriormente neste texto, ou seja, em um desenvolvimento profissional que se constitui por mudanças conceituais e comportamentais do professor frente ao seu instrumento 
de trabalho - o conhecimento pedagógico -, que, em nosso entendimento, são reflexões científicas direcionadas para uma transformação dessa atividade em uma práxis.

Desse modo, Buscariolo (2015) e Lopretti (2013) trazem para o diálogo a relação entre formação do professor e prática profissional, elegendo o cotidiano escolar especificamente a relação entre ensino do professor e aprendizagem dos alunos - como lócus de desenvolvimento profissional. São pesquisas realizadas pela égide metodológica do conceito de professor pesquisador, segundo a qual o próprio professor investiga e produz conhecimento sobre sua prática (ESTEBAM, ZACCUR, 2002).

Para Buscariolo, (2015) o olhar investigativo centra-se na relação entre a escolha do professor em usar instrumentos que potencializam a aprendizagem da leitura e da escrita como a escrita do texto-livre de Freinet (1976) - e a problematização dessa escolha, oferecendo subsídios para que a própria professora se torne pesquisadora de sua atividade pedagógica. Já para Lopretti (2013), a problematização da experiência prática da professora se ancora em sua relação com seus alunos, os quais também se tornam atores do próprio processo de avaliação da aprendizagem. É importante destacar que, em ambas as pesquisas, a mediação pedagógica é compreendida como instrumento primordial na práxis dessas professoras e se remodela pelo olhar do próprio estudante que faz parte desse contexto. Nesse viés, as relações de ensino ${ }^{3}$ tornam-se contextos de diálogo e expressão de sentidos sobre o cotidiano escolar entre professores e alunos.

Outra temática recorrente nos trabalhos científicos sobre a formação continuada do professor é o papel da coletividade docente, uma qualidade na relação entre professores de uma mesma instituição educacional que pode possibilitar uma reflexão mais ampla da realidade escolar vivenciada, com vistas a modificações das práticas pedagógicas (ANJOS, 2013; ANJOS E DAINEZ, 2018; BRITO E ARAUJO, 2018).

Na pesquisa de Anjos (2013), por exemplo, a coletividade docente se inicia por uma parceria entre investigador e um grupo de professores, permeados por uma proposta de reflexão sobre a prática docente no intuito de problematizarem coletivamente as relações e os sentidos produzidos sobre a prática pedagógica prescrita e objetivada (ANJOS, 2013). Com isso, o coletivo docente é entendido como um vínculo entre os professores que "afeta a atividade de ensinar" (ANJOS E DAINEZ, 2018, p. 107). Por isso, as autoras esclarecem que

\footnotetext{
${ }^{3}$ Usamos o termo "relações de ensino" no lugar da expressão "ensino e aprendizagem" ancorados nos estudos de SMOLKA (1991, 2000), cuja problematização sobre o processo de desenvolvimento humano, no processo escolar, transcende o processo de ensinar e aprender e é formado por muitas tramas relacionais.
} 
"fortalecer o coletivo de trabalho na instituição pública é, portanto, fundamental para a organização da ação do sujeito, sendo que com a organização da ação do sujeito tem-se a possibilidade de organização da ação da atividade de ensino. (ANJOS E DAINEZ, 2018, p. 107). Nesta perspectiva, a sistematização das atividades e as relações de ensino, engendradas cotidianamente, passam a ser compreendidas como lócus de uma práxis docente, lugar privilegiado de transformação da realidade e ressignificação de discursos.

Encontramos, também, em pesquisas vinculadas à temática da formação continuada do professor, o uso de determinados instrumentos, como, por exemplo, o portfólio reflexivo e a narrativa escrita. Sobre o portfólio, Sá-Chaves (2004) considera que tais instrumentos permitem ao sujeito evidenciar sua auto-reflexão, sua aprendizagem e seu desenvolvimento pessoal e profissional, pois é elaborado a partir das vivências mais significativas para os sujeitos, representadas por reflexões teóricas, relatos de experiência e problematização das mesmas e, também, pelos recursos imagéticos, tornando-se, assim, uma produção subjetiva e singular sobre o processo formativo vivenciado.

A narrativa surge, também, como um recurso de observação dos sentidos produzidos pelos professores, quando estes se propõem a problematizar as mais diversas experiências ao longo de seu percurso profissional. Por isso, por se tratar de uma escrita pessoal, a narrativa reflexiva pode se tornar um contexto no qual se revela um processo formativo do professor, ou seja, um movimento de mudanças em seus conceitos sobre ensinar, sobre a aprendizagem dos alunos, sobre a organização das ações didático-pedagógicas e, ainda, sobre o modo como compreende a relação que ele estabelece entre sujeito e produção do conhecimento.

Galvão $(2000,2005)$ e Josso (2004) também enfatizam que esse modo de refletir - que é, na verdade, um modo de problematizar as vivências - contribui de maneira singular para que o professor reconheça, signifique e reelabore os significados de suas experiências, em um movimento de projetar, avaliar e resignificar a sua própria formação na/pela escrita. Além disso, o professor pode se perceber o protagonista de sua formação ao assumir um olhar reflexivo e problematizador sobre sua experiência, o que implica em um modo outro de significação. Contudo, isso corresponde também a implicar-se em determinadas atitudes frente à sua própria aprendizagem docente, tornando-se um sujeito consciente, na perspectiva de, primeiro, (re)conhecer uma percepção própria da realidade na relação com seus anseios profissionais e, em seguida, por meio deles, imergir em propostas que o levem a se apropriar do conhecimento acerca de sua prática. 
Dada a singularidade da narrativa reflexiva na investigação sobre a formação inicial ou continuada de professores, esse instrumento tem sido relacionado, com frequência, à modalidade de pesquisa autobiográfica: uma visão de investigação que valoriza a relação entre a história de vida pessoal e a profissional na constituição da identidade do professor e na qualidade de seu processo formativo - que se torna contextualizado, histórico e relacional. Além disso, a narrativa pode ser utilizada tanto como metodologia de investigação quanto como lócus de análise do fenômeno analisado, conforme encontramos em algumas pesquisas que realizamos (MARTIN, 2010; MARTINEZ, MOURA, 2017).

A gênese da reflexão como processo de formação e/ou desenvolvimento profissional se encontra nos estudos inovadores de Jonh Dewey $(1979,2011)$ sobre o papel autônomo do sujeito em seu próprio processo de produção do conhecimento no ínicio do século XX. Essa nova possibilidade de compreender o processo educativo influenciou Donald Schön (2000) em seus estudos sobre os professores e seus processos formativos. Desse modo, o referido autor elaborou a noção da reflexão como atitude que avalia, cria e reorganiza a prática profissional cotidiana.

Partindo das ações vividas em sala de aula, a reflexão passa por três importantes movimentos: reflexão na ação, para a ação e uma metarreflexão, que seria um olhar analítico sobre todo o processo. Porém, essa nova epistemologia da prática docente desencadeou muitas avaliações críticas (PIMENTA, 2008; ZEICHNER, 1993, 2008), porque a reflexão das vivências cotidianas na atividade profissional do professor recai sobre o percurso isolado dessa reflexão e, tanto para Zeichner (1993, 2008), como para Pimenta (2008), a atividade docente vai além de uma prática individual, mesmo que seja um processo próprio de reflexão sobre o trabalho realizado.

Para Zeichner (1993, 2008), a reflexão sobre a atividade profissional docente precisa estar vinculada ao contexto sócio cultural desta atividade, ou seja, às situações concretas que a formam, representadas pelos modos de constituição das relações sociais, dos discursos que a orientam e a permeiam, de um habitus (BOURDIEU, CHAMPAGNE, 1998; ANJOS, 2013) constituinte dessas práticas. Com isso, Zeichner (1993, 2008) nos revela que as ações inerentes à atividade profissional do professor - como, por exemplo, as atividades pedagógicas - podem reiterar ou modificar discursos e práticas que não se modificam há algum tempo e que não se tornaram práxis, dependendo do modo como o próprio professor olha para elas. Por isso, enfatiza que, além do processo reflexivo individual, há a necessidade 
de uma reflexão dada por/em um processo coletivo. Portanto, ações reflexivas sobre as experiências profissionais precisam contribuir para que o professor vislumbre suas escolhas teóricas, práticas e, para além disso, para que compreenda que a problematização dessas vivências é uma possibilidade avaliativa das relações de ensino em sala de aula, as quais, por sua vez, constituem-se, também, pelo modo como os estudantes se relacionam com o conhecimento e com as ações que visam à sua aprendizagem.

Ressaltamos que é de extrema importância que esse processo de reflexão se relacione às teorias balizadoras dos processos educativos, se não a exacerbação das experiências, distanciadas de uma análise da relação entre sujeito e produção de conhecimento, pode gerar ciclos formativos aquém do conhecimento sociocultural, e este conhecimento é um importante instrumento para se apropriar, analisar e provocar mudanças nas situações sociais - muitas vezes reproduções de práticas hierarquizadas..

\section{A significação pelo enfoque da psicologia Histórico Cultural.}

O conceito teórico que nos mobiliza na presente reflexão é o processo de significação, ou seja, o modo como o sujeito elabora ou reelabora os sentidos de sua experiência, e como esses sentidos afetam seu comportamento. Trata-se de um conceito oriundo de um modo de compreender o desenvolvimento humano, que passa pelo seu processo histórico e social de constituição mediado pela linguagem.

A significação é um conceito presente em outras áreas do conhecimento - como a Linguística -, porém, apoiamo-nos na elaboração conceitual sobre a significação na psicologia Histórico Cultural, especificamente, nas obras de $\operatorname{Vygotsky}^{4}$ (2004, 2008) e Vigotski (2009). Portanto, trata-se de um conceito que envolve uma visão sobre a constituição do psiquismo humano com origem nas/pelas relações sociais mediadas.

Evidencia o autor que as funções psicológicas superiores - pensamento, linguagem consciência, entre outros - são relações sociais internalizadas, e justifica essa afirmação ao se reportar para o desenvolvimento psíquico da criança. Assim, Vigotski (2010) afirma que as

\footnotetext{
${ }^{4}$ A grafia do nome de Vygotsky sofre modificações dependendo da tradução feita, o que representa grafias como Vigotski, Vygotski, entre outras. Com isso, optamos, nas citações neste artigo, por manter a escrita do sobrenome do autor de acordo com a tradução da obra consultada.
} 
funções psicológicas superiores da criança, as propriedades superiores específicas ao homem, surgem a princípio como formas de comportamento coletivo da criança, como for- mas de cooperação com outras pessoas, $e$ apenas posteriormente elas se tornam funções interiores individuais da própria criança.(VIGOTSKI, 2010, p. 699, itálico do autor)

Com isso, o surgimento dessas funções psicológicas superiores é decorrente e constituinte das relações sociais, sendo que a significação tem um importante papel nesse processo na medida em que é por ela que os sentidos sobre a realidade são constituídos e reverberam como material de constituição do pensamento e da consciência. Porém, essa significação não é um processo linear e simplificado: ela é mediada pela linguagem e é, também, tensional e dialética.

Além disso, trata-se de um processo materialista e histórico porque ocorre nas relações sociais, criadas e datadas historicamente, e sempre será mediada por instrumentos e/ou signos. Portanto, todo processo de significação passa pela internalização de aspectos do mundo externo, e, consequentemente, toda produção de sentidos, passa, necessariamente, por um processo de mediação, internalização e de apropriação (SMOLKA, 2000), singular a cada sujeito.

Geraldi, Fichtner e Benites (2006, p. 19) nos apontam que a dinâmica relacional de produção de sentidos no sujeito também mobiliza uma consciência de ações temporais, pois desenvolver-se também é considerado pelos autores como "um diálogo initerrupto do sujeito com o seu futuro, um futuro que sempre será por ser alcançado" (GERALDI; FICHTNER; BENITES, 2006, p. 19).

Retomamos a importância do surgimento da linguagem $^{5}$ verbal para o desenvolvimento psicológico humano, especificamente para a constituição das funções psicológicas superiores, como o pensamento. Ela é simultaneamente mediadora e constituinte de todo processo de significação. A linguagem verbal se realiza no significado da palavra, que se torna veículo de manifestação do pensamento. Esse significado é constituído por conceitos generalizados, cujos sentidos podem ser modificados à medida que são usados entre sujeitos, dadas condições sociais específicas. A palavra em si é neutra, mas o sentido que cada

\footnotetext{
${ }^{5}$ A linguagem para Vygotsky não é apenas a palavra como a conhecemos, mas o verbum, elemento que veicula sentidos. Existem diferentes tipos de linguagens, como a musical, a corporal, entre outras, e cada uma possui um signo que veicula sentidos - na musical temos a notação, na corporal, o sentido pelo gesto, etc. Neste artigo, apoiaremo-nos na linguagem escrita como meio de processos de significação e constituição dos sujeitos, especificamente do professor-formador.
} 
palavra carrega depende, estritamente, do contexto em que ela é proferida. Sobre esse aspecto, Bakhtin (2004, p. 94) nos esclarece que:

[...] o elemento que torna a forma lingüística um signo não é sua identidade como sinal, mas sua mobilidade específica; da mesma forma que aquilo que constitui a decodificação da forma lingüística não é o reconhecimento do sinal, mas a compreensão da palavra no seu sentido particular, isto é, a apreensão da orientação que é conferida à palavra por um contexto e uma situação precisos, uma orientação no sentido da evolução e não do imobilismo.

É importante destacar que, na obra de Vygotsky (2008), Vigotski (2009), surgem dois conceitos importantes cujas definições se aproximam, mas possuem naturezas diferentes: significado e sentido. O sentido é o conjunto de todas as generalizações possíveis de um conceito, e, como tal, é passível de mudanças, dada a natureza histórica e cultural de sua constituição. Então, podemos dizer que o sentido se relaciona ao contexto no qual é elaborado e, também, encontra na palavra sua forma de materialização/externalização.

Assim, a convergência entre pensamento e linguagem encontra no significado sua externalização, e esse, por sua vez, torna-se elo entre sujeito e meio social pela mediação da fala, e se materializa na/pela palavra, que pode ser o veículo de observação do pensamento. A escrita surge como outro sistema de representação de significados e sentidos sobre a realidade - um sistema de signos criados pela humanidade para a comunicação. Essa criação semiótica possibilitou aos mais diversos povos e comunidades a transmissão e perpetuação de suas produções culturais para as suas futuras gerações.

Assumindo o processo de escrita como um instrumento semiótico de mediação entre sujeito e experiência, sugerimos que a narrativa, sendo uma estrutura lógica textual que tem como objetivo expressar a pessoalidade de uma experiência vivida ou ouvida por um determinado sujeito ou grupo social, pode assumir um caráter de significação, no qual o sentido da palavra em uso reverbera as relações concretas que o produziram; ou seja, o sentido compõe um significado elaborado pela experiência e "materializado" pela palavra.

Nesse sentido, os escritos de Benjamin (1994) sobre a narrativa corroboram com a concepção da narrativa como modo de de transmissão de experiências e elaboração de sentidos. Para o autor, esse instrumento torna-se um contexto de revelação de processos históricos ao contribuir para que diferentes espaços-tempos sejam expressos, relacionados e (re)organizados pelo o autor que escreve. 
Por isso, a narrativa escrita, utilizada como meio para o processo de formação continuada docente, configura-se como um instrumento de mobilização dos sentidos das palavras, tornando-se um contexto que permite a significação das experiências ao colocar o sujeito-autor (o professor), em/na relação com suas próprias experiências pessoais e profissionais. Desse modo, propicia a ele uma imersão em uma dinâmica/movimento transformador e histórico de sua constituição. Diante disso, pelo conceito de significação em Vigotski (2009), a escrita em narrativa pode ser vista como um instrumento que permite a observação dos sentidos que formam a consciência de quem escreve, ou melhor, dos significados que cada palavra assume pelo sujeito no contexto de sua experiência. Por isso, sugerir ao professor que escreva sobre suas experiências é, de certo modo, colocá-lo em desenvolvimento profissional.

\section{Um olhar metodológico para o processo de significação}

A análise sobre a ação de significar, proposta neste texto, parte do conceito de que o modo de olhar de um sujeito sobre sua ação é constituído, também, pelo olhar do outro - o externo, aquele com quem se relaciona. Ou seja, significar resulta da relação do sujeito com o meio sociocultural, especificamente pela atividade do trabalho.

Mas o que é o significar na prática de um professor-formador? É um todo de muitas tramas. Por isso, é dar sentidos, ou transgredir os sentidos iniciais, após o afastamento do contexto observado; é gerar novos conceitos ou possibilidades de sentidos, compreendendo o todo por suas partes; é imergir em um processo indiciário de buscas de uma relação de sentidos que envolveram o planejar e a realização de ações; é desvelar uma dinâmica reflexiva das experiências pessoais e profissionais que o formam; é uma tentativa de olhar o mundo real pelo prisma dos significados que o constituem. Enfim, é um processo singular. Por isso, significar parte de um contexto ou de um lugar que se relaciona ao lugar e contexto de quem olha.

Foi por essa perspectiva que o Paradigma Indiciário de Ginzburg (2003) nos auxiliou no processo de análise dos registro da professora-formadora e foi utilizado também por ela como uma orientação na (re)organização dos encontros constituintes dos cursos. Se havia uma busca dos significados sobre a formação docente presente nesses registros escritos, bem como a hipótese de que a professora-formadora produziu diferentes sentidos formativos na relação 
com esses espaços - e tais sentidos influenciaram suas novas ações dentro do planejado -, a metodologia de pesquisa escolhida deveria propor um olhar investigativo sobre os elementos do discurso que sustentassem a existência do fenômeno investigado.

Uma proposta de investigação indiciária nos orientou a escolher determinados elementos e contextos para a análise. Por isso, escolhemos, como unidade de estudo os indícios de constituição de um processo de significação da professora-formadora em relação ao processo formativo proposto nos cursos, os elementos textuais - como jargões, frases, palavras isoladas - cujos sentidos se interrelacionam, e o resultado desse elo pode ser um significado que orientou uma possível (re)organização das atividades subsequentes no curso.

O investigador, nessa perspectiva, deduz relações significantes no discurso, buscando rastros, pistas ou sinais de constituição do objeto na interrelação de sentidos. Esse modo de analisar se assemelha às ações de um pintor quando, a cada pincelada, utilizando cores distintas, vai produzindo uma imagem e, ao final, no conjunto de pinceladas, o quadro.

A princípio, adentrar em significados isolados pode definir a inexistência dos rastros de produção do fenômeno, mas a sua constituição pode estar fragmentada em "pistas", muitas vezes negligenciadas por olhares desatentos; por isso, Ginzburg (2003) revela que, nesse método de investigação, é imprescindível que o pesquisador esteja imerso no contexto que, $a$ priori, produz o objeto de análise e que desenvolva um "olhar" atento para o que procura entender.

Assim, investigar com base nos indícios é, preferencialmente, uma pesquisa qualitativa-participante. É importante destacar que a análise indiciária pode passar pela produção de uma narrativa histórica de constituição do fenômeno, em função da necessidade de o investigador adentrar na produção discursiva temporal que o revela.

Investigar de maneira indiciária pressupõe, também, que o olhar do pesquisador esteja sustentado por uma perspectiva teórica de análise, pois, se o objeto investigado parte de um conceito de existência - como, neste texto, por exemplo, os significados sobre a formação docente pelo olhar do professor-formador passam pelo crivo de uma definição de produção de significado presentes nos estudos de Vygotsky (2008), Vigotski (2009) -, a construção da narrativa histórica de existência desse fenômeno segue esta lógica.

Assim, para este texto, apresentaremos, primeiramente, o discurso, presente em três textos-registros de uma professora-formadora, quando descreveu encontros realizados em espaços-tempos distintos (nos anos de 2012 e 2013). Em seguida, apresentaremos, por meio 
de uma narrativa, os indícios de constituição do objeto, percebidos na escrita, que sustentam nossa hipótese inicial, qual seja: a existência de elementos discursivos que revelem que os sentidos da professora-formadora sobre a qualidade do processo de formação docente foram se constituindo na/pela relação com os participantes. Esse modo outro de apresentar os dados, em uma perspectiva histórica, é uma tentativa de compreender se a reformulação dos encontros foi orientada, a cada escrita, pela produção de sentidos singulares sobre a formação docente.

\section{Os textos-registros: um modo outro de narrar.}

\subsection{Planejamento 1 - caderno de registro}

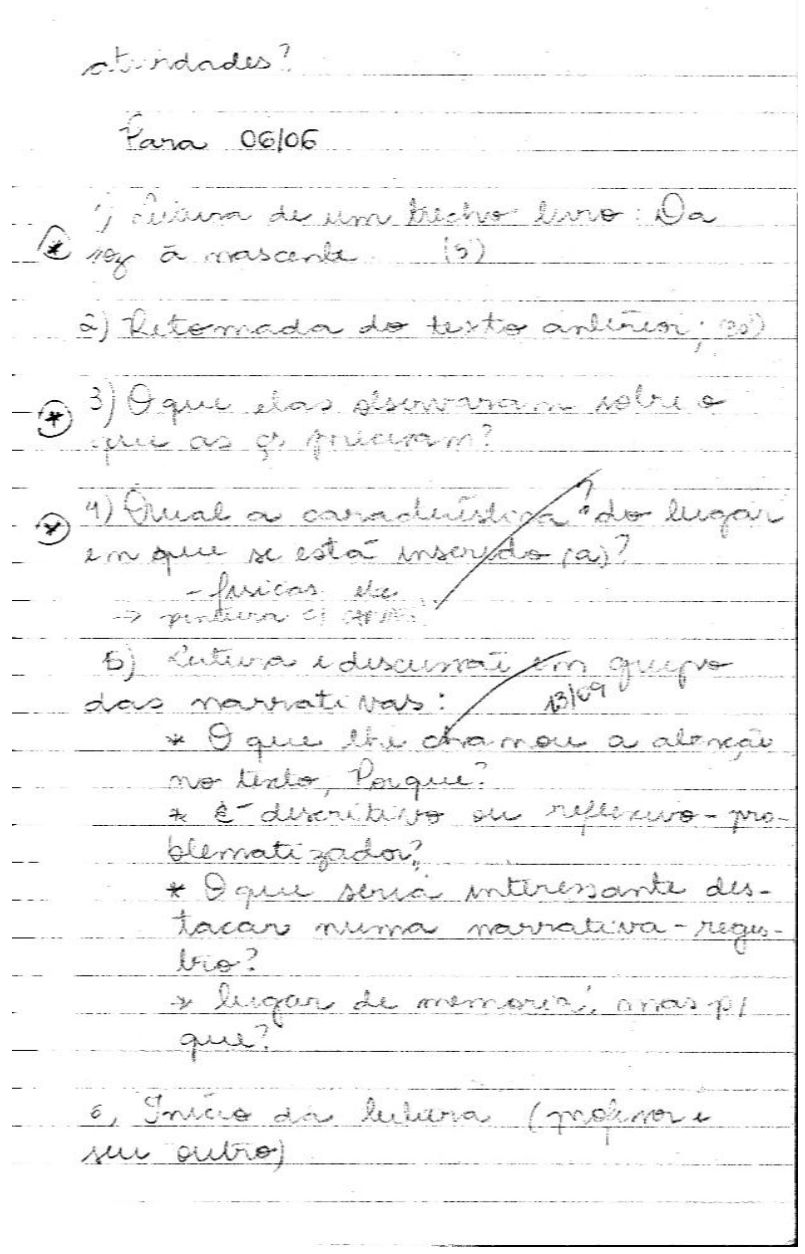

Atividades?

Para 06/06

1) Leitura de um trecho do livro:

Da foz à nascente (5)

2) Retomada do texto anterior

3) O que elas observaram sobre o que as çs (crianças) precisam?

4) Qual a característica do lugar em que se está inserido (a)?

-físicas, etc. - pintura c/ carvão

5) Leitura e discussão em grupo das narrativas:

- o que lhe chamou a atenção no texto, por quê?

- é descritivo ou reflexivo problematizador?

- o que seria interessante destacar numa narrativaregistro?

- lugar de memória, mas / quê?

6) Início da leitura (Professor e seu outro)

Imagem 1: imagem da narrativa 1 do caderno de registros da professora-formadora. 


\subsection{Narrativa 2 - caderno de registros}

Eu havia planejado muitas atividades para hoje. A lista de itens se estendeu até $o \mathrm{n}^{\circ} 6$. Ler o texto novo, rever o antigo, ler narrativas, fazer atividade com carvão. Conversamos sobre o planejar... outras companheiras chegaram. Conheço um pouco delas, elas me conheceram também. Foi um dia bem legal. Me senti um pouco preocupada se darei conta do que propus, mas ao mesmo tempo percebo que o "rio segue seu caminho" e este é belo unicamente por ser singular. Assim nosso caminho está sendo feito ao caminhar. Estou um pouco sem ideia para escrever. Percebo que planejar está vinculado ao tempo, à qualidade e à disponibilidade dele. E também ao gostar. Todas estão aqui porque se sentem interessadas no tema. Por aspectos diferentes buscam o curso. Mas o interesse é o mesmo: conhecer. E isso também está me guiando: ler mais, conhecer mais para poder proporcionar a elas um ambiente seguro de partilha. Para o próximo encontro ficou a leitura das narrativas e a explicação do portfólio e continuação do texto do planejamento. Acho que vou iniciar o próximo encontro com a leitura do texto do livro "Da foz à nascente"(UNGER, 2001) e depois continuar a leitura. Pedi a elas a escrita de 2 textos: o que é planejamento e registro e do como me vejo onde estou. (Caderno de registros da professora-formadora, set/2012)

Os registros $1^{6}$ e 2 se completam, visto que o primeiro se refere às atividades planejadas pela professora-formadora no intuito de desenvolvê-las ao longo de um dia de curso. E o segundo evidencia uma reflexão sobre o planejamento feito e expresso no primeiro texto. Em uma primeira leitura dos dois textos, observamos que ocorreram mudanças entre aquilo que foi planejado durante o curso - quando iniciaram os diálogos com os professores participantes - e aquilo que pôde ser realizado. A professora-formadora não evidencia quais necessidades dos professores fizeram com que ela mudasse o seu planejamento, mas é possível compreender tanto pelas marcas mnemônicas ${ }^{7}$ em seu planejamento (Planejamento 1), como por sua narrativa escrita (Narrativa 2) que ocorreu uma reorganização dos objetivos

\footnotetext{
${ }^{6}$ Optamos em deixar o registro 1 em imagem visto que apresenta as marcas mnemônicas da professoraformadora para posteriormente se lembrar do que deveria (re) planejar. Essas marcas são significantes à medida que expressam uma ação de (re) organização de sua ação no encontro.

${ }^{7}$ As marcas mnemônicas a que nos referimos são os sinais criados pela professora-formadora para demarcar em seu texto de planejamento o que foi realizado (representado pelos traços que cortam as palavras) e qual tópico deveria ser retomado no próximo encontro (representado pelo sinal asterisco do lado do ítem). Para Vigotski (2009), o processo de significação passa, necessariamente, pela criação de signos como instrumento psicológico que medeiam a relação entre sujeito e o significado de um objeto psíquico.Com isso, o uso desses signos pela professora-formadora nos revela um modo de significar, de dar sentido de ação, de organização de seu planejamento.
} 
formativos por uma demanda dos participantes, e isso demonstra que alguns objetivos foram significados pela relação estabelecida inicialmente com as participantes do curso.

Outro exemplo dessa reorganização do planejamento pode ser representado pela marcação realizada no item 5 do Planejamento 1: a data inserida (13/09) define a reorganização da atividade de Leitura e discussão em grupo das narrativas, que ainda continha seus subitens, para o encontro subsequente. Essa hipótese pode também ser confirmada quando, na Narrativa 2, a professora-formadora esclareceu o que havia planejado e o que mudou: Eu havia planejado muitas atividades para hoje. A lista de itens se estendeu até $o n^{\circ} 6$. Atividades que não foram realizadas visto sua reorganização apresentada pela figura 1. Adiante, na Narrativa 2 a professora-formadora descreve um sentimento que a afligiu quando se pôs a escrever, e que pode se relacionar ao modo como concebe sua atuação: uma ação que precisa "dar conta" das tarefas inicialmente pensadas - sentimento oriundo da experiência com o primeiro encontro e que indica, também, o seu envolvimento com a proposta formativa. Além disso, expressa, de certo modo, um olhar do professor como aquele que precisa deter todo o conhecimento e que apenas orienta - uma concepção que se aproxima de um modo tradicional de compreender a relação entre produção de conhecimento e sujeito.

Dar conta pode representar, também, estar qualificada para tal ação, e isso revela uma insegurança da professora-formadora em relação ao modo como conduzirá o curso. O uso desse termo ("dar conta") nos indica que surge uma problematização de sua própria ação como formadora, um movimento que mobiliza sentidos relacionados a sua experiência profissional com as crenças sobre ser um bom professor

A princípio, sua escrita oferece indícios de que essa angústia pode ter sido resolvida nas elaborações de sentidos subsequentes, quando atribui um sentido de constante elaboração para sua atação como formadora - momento em que utiliza uma expressão poética: “o caminho se faz ao caminhar". Assim, revela-nos: Me senti um pouco preocupada se darei conta do que propus, mas ao mesmo tempo percebo que "o rio segue o seu caminho" e este é belo unicamente por ser singular. Assim, nosso caminho está sendo feito ao caminhar"

É pelo movimento de narrar que esses sentidos são mobilizados; portanto, há indícios de que a reflexão é um processo inerente ao percurso de significação sobre o que a professoraformadora vivenciou como sujeito responsável pela formação de outrem. Esse narrar resgata experiências datadas historicamente, vinculadas a um contexto específico formativo, e as 
relaciona às próprias expectativas dessa professora-formadora, o que também nos revela um processo de formação de consciência.

Sadalla e Sá-Chaves (2008, p. 191) nos esclarecem que no processo de reflexividade docente "é imprescindível que o professor, durante o seu desenvolvimento profissional, tenha condições de gerenciar estes dilemas" e essas narrativas representam um modo de enfrentamento dos dilemas que surgem na prática da professora-formadora, quando esta se coloca em reflexão sobre sua experiência de planejar e realizar as atividades do curso.

Na Narrativa 2, ainda, existem indícios de um processo de significação sobre a organização de cada momento do curso, representadas pelos encontros individuais. Tratam-se, para ela, de possibilidades de agir, não imutáveis, que, metaforicamente, podem seguir seu caminho como um rio, cujo curso das águas se molda frente aos obstáculos do relevo. Então, seu planejamento passa a ser elaborado no e pelo percurso do próprio curso, que ocorre em/na relação com os participantes.

Consideramos que o uso da metáfora "o rio segue o seu caminho" é um desabafo e uma tentativa de se "conformar" com as mudanças que percebeu ser inerentes ao desenvolvimento do curso de formação continuada, dadas as experiências vivenciadas nele. $\mathrm{O}$ sentido dessa metáfora pode ser compreendido também pelo complemento de sua escrita, ao utilizar a frase "e este é belo unicamente por ser singular. Assim nosso caminho está sendo feito ao caminhar" (Narrativa 2). É a mudança de olhar que revela um processo de constituição da consciência sobre o sentido de sua própria atuação como professoraformadora.

Ainda, em seu texto, apresenta-nos outra alternativa possível de interpretação do ocorrido: assim como um rio, sua proposta se "molda" em relação à realidade, às expectativas e também ao tempo possível de realização de cada encontro ${ }^{8}$. O uso dessa metáfora pode se relacionar à angustia em dar conta das ações, pois, à medida que (re)significa sua ação pronta para uma ação em mudanças, aberta às oportunidades, como um rio em movimento, problematiza que "dar conta" pode não ser uma ação que se realiza. Com isso, demonstra que surgiu nela (ou já existia e se tornou consciente) uma abertura às incertezas e ao inesperado, significado que pode ser observado quando usa a frase o caminho se faz ao caminhar.

\footnotetext{
${ }^{8}$ Cada encontro foi realizado por $2 \mathrm{~h} 30 \mathrm{~min}$, uma vez na semana, a cada semestre.
} 
Perceber o curso por ela ministrado como o trajeto de um rio indica também que a realização de sua intenção, mesmo passando por modificações, de algum modo atingirá seu objetivo, pois um rio sempre chega ao seu objetivo: desaguar no mar. Possibilita-nos, ainda, interpretar que se inicia, em seu discurso, uma significação sobre o trajeto a ser seguido, pois o importante pode ser, na verdade, o caminhar, a dinâmica, e isso pode envolver, também, todos os elementos que ajudam os sujeitos nesse trajeto - no caso do curso: o referencial teórico, os diálogos, as trocas de experiências, os instrumentos reflexivos, entre outros. Então, a ênfase na "construção" desse caminhar elucida que o significado do planejar mudou: revelase agora na/em relação ao contexto externo e não apenas às aspirações da professoraformadora. Novamente, é na articulação com a escrita de modo narrativo que o pensamento da professora-formadora vai sendo mobilizado e revelado, como corrobora Galvão (2005)

\footnotetext{
A narrativa como processo de investigação, permite-nos aderir ao pensamento experiencial do professor, ao significado que dá às suas experiências, à avaliação de processos e de modos de atuar, assim como permite aderir aos contextos vividos e em que se desenrolaram as ações, dando uma informação situada e avaliada do que se está a investigar. (GALVÃO, 2005, p.343)
}

Com isso, as narrativas da professora-formadora tornam-se lócus de análise dos sentidos sobre sua experiência.

Pela égide da significação, se a teoria Histórico-Cultural (VYGOTSKY, 2008) nos oferece subsídios para compreender o desenvolvimento humano pelas relações sociais, da interrelação (com o outro), da intra-relação (consigo mesmo), mediado pelos signos, compreendemos que, nesse percurso inicial, a professora-formadora significou o seu planejamento como um instrumento passível de ser modificado, dada a experiência desse encontro. Com isso, abriu mão de seu planejamento inicial, remodelando-o de acordo com o que pôde vivenciar.

A escolha em mudar, de certo modo, não contemplou um motivo pessoal da professora-formadora, representado pelo seu planejamento inicial; pelo contrário: esteve ligada às demandas dos seus outros-professores. Isso demonstra que o sentido dado ao processo de formação continuada, que a professora havia proposto, passou pelo seu olhar atento às necessidades de diálogo e aprendizagem sobre o fazer docente daquele grupo de professores.

O processo de significação sobre a formação continuada docente - ou seja, de produção de sentidos sobre esse contexto - deu-se tanto na/em relação com a experiência dos outros professores como pela sua própria experiência reflexiva na narrativa a posteriori. É a 
mediação surgindo no processo de formação docente da professora-formadora como modo de organização do pensamento pela linguagem - no diálogo verbal (falado/escrito).

Outra questão importante a ser ressaltada sobre a significação das ações da professoraformadora revela-se na seguinte frase: Todas estão aqui porque se sentem interessadas no tema. Por aspectos diferentes buscam o curso. Mas o interesse é o mesmo: conhecer. E isso também está me guiando: ler mais, conhecer mais para proporcionar a elas um ambiente seguro de partilha. A professora-formadora percebeu, pelo discurso dos professores, que a maioria se mostrava interessada pela proposta do curso - dialogar e realizar o planejamento de atividades pedagógicas para a Educação Infantil - e perceber esse envolvimento nos participantes a estimulou no estudo e preparação de modos outros de intervenções.

Com isso, sua ação tornou-se importante para ajudar os educadores em suas questões fato observado quando revelou que isso também está me guiando. Como consequência, propõe-se a estudar mais, para que o ambiente de formação continuada seja realmente significante para os professores e, de certo modo, também para ela. Por isso, entendemos que foi na relação com o outro - professor, educador e consigo mesmo, pois todo discurso é um discurso de outrem, como diria Bakhthin (2004) - que a professora-formadora significou a modificação de seu planejamento como ação importante para a promoção desse contexto de desenvolvimento profissional.

O saber fazer como professora-formadora, ou seja, o processo de significação sobre o seu fazer, foi sendo constituído à medida que ela foi problematizando as experiências e, com isso, elaborando novos sentidos sobre o que para ela seria uma formação profissional enquanto um processo de desenvolvimento humano. Em sua escrita, expressa que o contato com o objeto real, a dinâmica do curso, desestabilizou o sentido de certeza de suas ações, e isso pôde ser percebido pela escrita da Narrativa 2. Esse processo se aproxima do que Vygotsky destaca sobre a significação: "um fenômeno do pensamento apenas na medida em que o pensamento ganha corpo por meio da fala, e só é um fenômeno da fala na medida em que é ligada ao pensamento, sendo iluminada por ele" (VYGOTSKY, 2008, p. 151).

\subsection{Narrativa 3 - Caderno de Registros 3}

Iniciamos com a dinâmica de desenhar um objeto pela descrição de um colega. Este com a mão em uma sacola, sentia o objeto e o descrevia: suas formas. Descrever o que sentia para o outro desenhar. Foi bem interessante, cada uma com sua singularidade desenhou o que achou. Com essa dinâmica 
trouxe a questão do relato e interpretação: são ações fáceis? O que ficou? Todas trazem a questão de uma certa dificuldade em descrever, saber qual característica definir. Foi uma dinâmica bem legal! Deu para quebrar um pouco o meu falatório. Tem hora que acho que falo demais. Será que contribuo com alguma coisa? É valido para elas aquilo que falo? Algumas situações cotidianas foram levantadas, como, por exemplo, o desinteresse de muitos da equipe em realizar atividades diferentes. "Temos vontade de fazer, mas isso é barrado porque nem todo mundo quer fazer" uma coisa percebi: há uma motivação geral no grupo= a ânsia em fazer coisas novas, diferentes, em não continuar na mesmice. Consegui fazer as dinâmicas das leituras das narrativas: em pares elas leram as narrativas dos alunos de Pedagogia e conversamos um pouco sobre a impressão que tiveram sobre o que chamou a atenção no texto: texto descritivo ou narrativo?; o que seria interessante destacar numa narrativa?. Não conversamos sobre o lugar da memória porque achei que não era um tema que emergia do grupo. Falamos bastante sobre a maneira de registrar o que as crianças falam e fazem. As educadoras $\mathrm{X}$ e $\mathrm{Y}$ trouxeram a experiência de suas salas, o papel que registraram as ações das crianças. Como lidam com isso: cada monitor fica responsável por quatro crianças. No segundo semestre isso se modifica.Tive a ideia de pedir para cada uma elaborar uma maneira diferente de produzir o registro da fala das crianças. Pensei num móbile para minha sala. Semana que vem socializaremos essa experiência.

(Caderno de registros da professora-formadora, ago/2013)

A primeira dinâmica de escrita se refere a um exercício de expressão: comunicar-se utilizando outras maneiras, sem ser exatamente a palavra que define o objeto sentido pelas mãos. O objetivo da referida proposta foi revelar que nem sempre conseguimos compreender o outro, ou, ainda, exercitar o fazer-se compreender apenas pela escrita. Por isso, questiona se relato e interpretação: são ações fáceis?? Saber interpretar a própria experiência era importante para se elaborar uma narrativa (dada a pessoalidade dessa escrita), mas percebeu que justamente esse elemento era uma dificuldade relatada pelos participantes: Todas trazem a questão de uma dificuldade em descrever, saber qual característica definir. Ao perceber isso, (re)organiza sua ação e propicia um exercício de vivência de uma interpretação. Nota-se, com isso, que, novamente, o significado de um ambiente formativo propício e acolhedor, que visa a um desenvolvimento profissional, passa pelo ouvir as necessidades dos professores e educadores. Se havia uma necessidade em se expressar melhor, então planejou-se uma atividade com esse fim, relacionando também a expressão corporal com esse intuito.

Contudo, essa atividade foi direcionada, também, por outra necessidade, da professora-formadora: oferecer mais experiências do que "falatório". Deu para quebrar um pouco o meu falatório. Tem hora que acho que eu falo demais. Mas falar demais é ruim? Nesse momento, sim. Pode ser que essa dinâmica tenha resgatado memórias escolares nessa professora-formadora de um ensino unilateral. Ainda, parece que a professora-formadora 
tenta romper com um visão de formação passiva, oriunda de uma hierarquização do saber, na qual quem detém o conhecimento o transmite, sem levar em consideração as necessidades de aprendizagem dos sujeitos com os quais fala. Nesse desabafo, ela questiona suas atitudes de formadora e completa: Será que contribuo com alguma coisa? É válido para elas aquilo que falo?

A significação de sua prática como professora-formadora se relaciona estritamente com o seu fazer, como já mencionamos anteriormente. É nessa relação social de trabalho que os significados sociais do papel do professor vão se modificando para ela, ou seja, que os significados inerentes à sua ação vão recebendo uma outra qualidade. Antes, tratava-se apenas de uma transmissora para um sujeito próximo, ouvinte e também falante, mas quase que em uma ação terapêutica, visto que este sempre escuta para agir. Esse ouvir-atento pode ser elucidado quando relata que Algumas situações cotidianas foram levantadas [...]Temos vontade de fazer, mas isso é barrado, porque nem todo mundo quer fazer.

A sua atuação como professora-formadora gera em si mesma mudanças de comportamento. Internaliza, por meio da linguagem, os sentidos que cada participante expressa sobre quais elementos são importantes para serem dialogados em uma dinâmica de formação continuada. Essa situação nos faz aproximar dos escritos de Marx (1989) ao ressaltarem que, por meio do trabalho, com o uso de instrumentos, o ser humano modifica o meio e se modifica. No caso, o meio é social, e o instrumento, a linguagem (ROSA; ANDRIANI, 2011)

No decorrer do registro, a professora-formadora ressalta novamente a observância de motivos acerca das ações dos educadores no curso: todos apresentam uma necessidade em conhecer práticas novas, pois não querem continuar na mesmice. Isso pode ser um indício de que buscou pistas para fomentar novas ações no curso. Em seguida, enfatiza que uma ação planejada foi possível de ser realizada, a leitura de narrativas de outros sujeitos: Consegui fazer as dinâmicas das leituras das narrativas. Entretanto, parece que esta dinâmica estaria relacionada à outra: promover um diálogo sobre o lugar da memória nessa ação. No entanto, o que novamente ocorre é uma "mudança de planos": Não conversamos sobre o lugar de memória porque achei que não era um tema que emergia do grupo. Falamos bastante sobre a maneira de registrar o que as crianças falam e fazem. A tomada de um assunto novo esteve relacionado, novamente, à demanda do grupo de professores e educadores: maneiras outras de registrar as atividades realizadas com as crianças. 
Uma ação relatada no final de sua narrativa - Tive a ideia de pedir para cada uma elaborar uma maneira diferente de produzir o registro da fala das crianças. Pensei num móbile para minha sala - une-se a uma questão já levantada inicialmente em sua escrita: a percepção de que os professores queriam aprender modos outros de agir. Com isso, procura propor uma atividade diferenciada. Mas essa atividade não restringe apenas aos participantes do curso; estende-se à sua própria prática como professora, pois, concomitantemente ao curso, continua a exercer o magistério para crianças pequenas. Isso nos orienta a refletir sobre a importância que tem, para ela, o sentido de proximidade do seu trabalho com o trabalho dos professores e educadores. Se não, não haveria motivo para realizar tal atividade em sua sala de aula. E esse significado pode ser expresso quando diz: pensei num móbile para minha sala. Nesse sentido, a formação do outro, tanto da professora-formadora quanto das educadoras presentes no curso, passa também pelo olhar da professora-formadora sobre as necessidades, a (re)organização de seu planejamento e, ainda, pela proximidade de sua prática, como professora, às práticas delas.

\section{Considerações finais}

O presente texto buscou elucidar um processo de significação sobre a formação docente em um ambiente de formação de professores pelo olhar do professor-formador. Todos os registros escritos (planejamento e narrativas) da professora-formadora, apresentados neste texto como corpus de análise, continham elementos significantes que confirmaram uma ação de (re)organização do planejmaento inicial dos cursos - ou de cada encontro - visando a uma maior proximidade do referido contexto às necessidades colocadas pelo grupo-curso. Expressões como tive a ideia/ pensei/consegui fazer/será?/é válido?/acho que vou iniciar/isso também está me guiando encontradas em sua escrita, definem que a sua atuação como professora-formadora foi se (re)modelando pela experiência real no decorrer do curso, pelo desenvolvimento das atividades propostas e mais, ainda, por sua escrita sobre as impressões dialógicas do dia, elaboradas ao final de cada encontro.

O seu diário, ou caderno de registros, foi constituindo-se, para ela, como uma referência de atuação, memorização e transgressões de práticas docentes que enfatizam uma transmissão de conhecimento. Para além disso, ela buscou se reinventar a cada encontro, pelas necessidades formativas dos participantes. E isso ficou explícito quando, ao final do registro 
3 , descreveu às participantes do curso que também realizaria uma atividade de ensino com sua turma de crianças.

As intenções iniciais de atividade para cada encontro se modificaram e deram lugar às possibilidades de ação e interrelação tanto com as necessidades da própria professoraformadora - como sujeito mediador de um conhecimento - como com aquilo que os professores apresentaram como necessidade de discussão e problematização no curso. $\mathrm{Na}$ verdade, a ação de (re)planejar se configura como uma tentativa da professora-formadora em produzir um equilíbrio entre intenção inicial do curso e necessidades dos participantes. Isso demonstra que o planejamento de um curso de formação continuada é uma ação em mobilidade, e seus objetivos podem ser significados quando postos em/na relação com outros sujeitos.

Os registros apresentados neste texto foram produzidos a partir de diferentes contextos formativos, como mencionamos no início, mas que se complementaram quando buscamos compreender como a professora-formadora significou seu papel em cada ação. Tratam-se de espaços e tempos distintos, mas relacionais, que ilustram um mesmo intento: propiciar um ambiente formativo que produzisse sentidos de aprendizagem naqueles que dele fizeram parte. Com isso, fica a questão: quem significou a formação docente foi mesmo a professoraformadora?

\section{Referências Bibliográficas}

ANJOS, D. D. dos. O trabalho docente em questão: gênero de atividade, gênero de discurso e habitus. 2013. 236f. Tese (Doutorado em Educação) - Faculdade de Educação, Universidade Estadual de Campinas, Campinas. 2013.

ANJOS, D.; DAINEZ, D. . A construção da prática docente: reflexões sobre a relação entre a ação individual e o contexto social. Revista de Educação Pública, v. 27, p. 91-108, 2018. Disponível em: http://periodicoscientificos.ufmt.br/ojs/index.php/educacaopublica/article/view/3724/pdf. Acesso em: 24 ago 2019.

ARAUJO, E. S.. O Projeto Pedagógico como (Des)encadeador do Trabalho Coletivo na Escola. Educação. Teoria e Prática (Rio Claro), v. 26, p. 63-72, 2006

BAKHTIN, M. Marxismo e Filosofia da Linguagem: problemas fundamentais do método sociológico na ciência da linguagem. Tradução Michel Lahud e Yara Frateschi Vieira. São Paulo: Hucitec, 2004. 
BENJAMIN, W. Obras Escolhidas - magia e técnica, arte e política. 7. ed. São Paulo: Editora Brasiliense, 1994.

BOURDIEU, P.; CHAMPAGNE, P. Os excluídos do interior. In: NOGUEIRA, M.A.; CATANI, A (Org.). Pierre Bourdieu: Escritos de educação. Petrópolis: Vozes, 1998. p. 217227.

BUSCARIOLO, A. F. V. T. O texto livre como instrumento pedagógico na alfabetização de crianças. 2015. 193f . Dissertação (Mestrado em Educação) - Faculdade de Educação, Universidade Estadual de Campinas, Campinas. 2015.

BRITO, K. D. M. ; ARAUJO, E. S . Princípios e possibilidades da formação docente na perspectiva do trabalho coletivo. Obutchénie. Revista de Didática e Psicologia Pedagógica, v. 2, p. 591-617, 2018. 2 Disponível em: http://www.seer.ufu.br/index.php/Obutchenie/article/view/47434. Acesso em: 24 ago 2019.

DEWEY, J. Como pensamos: como se relaciona o pensamento reflexivo com o processo educativo; uma rexposição. 4. ed. São Paulo, SP: Nacional, 1979. 292 p. (Atualidades pedagógicas, v.2).

DEWEY, J. Experiência e educação. 2.ed. Petrópolis: Vozes, 2011. 165 p. (Textos fundantes de educação), v.15). ISBN 9788532639363 (broch.).

ESTEBAM, M. T.; ZACCUR, E. (Orgs). Professora Pesquisadora: uma práxis em construção. Petrópolis: 1 ${ }^{\text {a }}$. ed. Rio de Janeiro: DP\&A, 2002.

FREINET, C. O Texto Livre. Lisboa: Dinalivro Distribuidora Nacional, $2^{\text {a }}$ edição, 1976.

GALVÃO, C. Da formação à prática profissional. Inovação, Lisboa, v.13, n. 2, p 57-82, 2000.

GALVÃO, C. Narrativa em Educação. Revista Ciência e Educação, Bauru, v.11, n. 2, p. 327-345, 2005. Disponível em: http://www.scielo.br/pdf/ciedu/v11n2/12.pdf. Acesso em: 04 ago. 2008.

GERALDI, J. W., FICHTNER, B.; BENITES, M. Transgressões convergentes: Vigotski, Bakthin, Beteson. Campinas: Mercado das Letras, 2006.

GINZBURG, C. Mitos, emblemas, sinais: morfologia e história. Tradução Frederico Carotti. São Paulo: Companhia das Letras, 2003.

JOSSO, M. C.Experiência de vida e formação. São Paulo: Cortez, 2004.

LOPRETTI, T. A. P. E os saberes das crianças ensinam à professora: contribuições para o desenvolvimento pessoal e profissional docente. 2013. 307f. Tese (Doutorado em Educação) - Programa de Pós-Graduação em Educação, Universidade Estadual de Campinas, Campinas, 2013. 
LÜDKE, M.O professor, seu saber e sua pesquisa. Educação \& Sociedade, ano XXII, $\mathrm{n}^{\circ} 74$, Abril de 2001. Disponível em: http://www.scielo.br/pdf/es/v22n74/a06v2274. Acesso em 21 ago 2018.

MARTIN, A. O. de O. Significados e sentidos sobre os processos formativos de estudantes de Pedagogia. 2010. 185f. Dissertação (Mestrado em Educação) - Programa de PósGraduação em Educação, Universidade Estadual de Campinas, Campinas, 2010.

MARTINEZ, A. O. de O. M.; MOURA, A. R. L. de. Uma reflexão sobre o uso da escrita em narrativa na formação inicial de estudantes de pedagogia para ensinar matemática. Perspectivas da Educação Matemática, v. 10, p. 349-365, 2017. Disponível em: https://periodicos.ufms.br/index.php/pedmat/article/view/1608. Acesso em dez 2017.

MARX, K. O método da economia política. posfácio $2^{a}$ edição de O Capital. In: Marx e Engels. Textos escolhidos. Florestan Fernandes, São Paulo: Ática, 1989

PIMENTA, S. G. Professor reflexivo: construindo uma crítica. In: PIMETNA, S. G.;GHEDIN, E. (Orgs) Professor Reflexivo no Brasil. Gênese e crítica de um conceito. 2. ed. São Paulo: Cortez, 2008.

ROSA, E. Z.; ANDRIANI, A. G. P. Psicologia Sócio- Histórica: uma tentativa de sistematização epistemológica e metodológica. In: KAHHALE, E. M. P. (Org.) A diversidade da psicóloga: uma construção teórica. 4.ed. São Paulo: Cortez, 2011. p 259288.

SADALA, A. M. F. de A., SÁ-CHAVES, I. da S. C.Constituição da reflexividade docente: indícios de desenvolvimento profissional coletivo. ETD - Educação Temática Digital, v. 9, n. 2, p. 189-203, 11 nov. 2008. Disponivel em : https://periodicos.sbu.unicamp.br/ojs/index.php/etd/article/view/826. Acesso em:10 dez 2012.

SÁ-CHAVES, I. Portfólios reflexivos: estratégia de formação e supervisão.2.ed. Aveiro: Universidade, 2004.

SCHÖN, D. A. Educando o profissional reflexivo: um novo desing para o ensino e a aprendizagem. Tradução: Roberto Cataldo Costa. Porto Alegre: Artmed, 2000.

SMOLKA, A. L. B. Múltiplas Vozes Na Sala de Aula: Aspectos da Construção Coletiva do Conhecimento Na Escola. Trabalhos em Lingüística Aplicada, CAMPINAS, SÃO PAULO, v. 18, n.18, p. 15-28, 1991.

SMOLKA, A. L. B. O (im)próprio e o (im)pertinente na apropriação das práticas sociais. Cadernos CEDES, Campinas, São Paulo, v. 1, n.50, p. 26-40, 2000.

UNGER, N. M. Da foz à nascente: o recado do rio. São Paulo; Campinas: editora da Unicamp. 2001

VÁZQUEZ, A. S. Filosofia da práxis. Tradução de Luiz Fernando Cardoso. 2.ed. Rio de Janeiro, Paz e Terra, 1977. 
VIGOTSKI, L. S. A construção do pensamento e da Linguagem. Tradução Paulo Bezerra. 2. Ed. São Paulo: Editora WMF Martins Fontes, 2009.

VIGOTSKI, L. S. Quarta aula: a questão do meio na pedologia. Tradução de Márcia Pileggi Vinha. Psicologia USP, São Paulo, 2010, 21 (4), 681-701. Acesso em: 12 mar 2018. Disponível em: http://www.revistas.usp.br/psicousp/article/view/42022.

VYGOTSKY, L. S. Teoria e Método em Psicologia. Tradução Cláudia Berliner. 3. Ed. São Paulo: Martins Fontes, 2004

VYGOTSKY, L. S. Pensamento e linguagem. 4. ed. São Paulo: Martins Fontes, 2008

ZEICHNER, K. M. A formação reflexiva de professores: idéias e práticas, Lisboa: Educa, 1993.

ZEICHNER, K. M. Para além da divisão entre professor-pesquisador e pesquisador acadêmico In: GERALDI, Corinta M.; FIORENTINI, Dario \& PEREIRA, Elisabete M. (orgs.) Cartografia do trabalho docente: professor(a)-pesquisador(a). Campinas, Mercado de Letras, ABL, 1998. pp. 207-236.

ZEICHNER, K. M. Uma análise crítica sobre a "reflexão" como conceito estruturante na formação docente. Educ. Soc. Campinas, v.29, n.103.p535-554, maio. /ago, 2008. 